\title{
Digital Board Game: Is there a need for it in language learning among tertiary level students?
}

\author{
Zuraina Ali ${ }^{1,}$, Mohd Amir Izzudin Mohamad Ghazali ${ }^{1}$, Rosnani Ismail ${ }^{1}$, Nurul Nadia Muhammad ${ }^{1}$, Noor \\ Azlinda Zainal Abidin and Nabila Abdul Malek ${ }^{1}$ \\ ${ }^{1}$ Centre for Modern Languages \& Human Sciences Department, Universiti Malaysia Pahang, 26600 Pekan, Pahang, \\ Malaysia
}

\begin{abstract}
The concept of learning while playing to learn language is a pedagogy that can enhance students' learning interest. In this digital era, the use of board games, for instance, has provided a solution to learning a language. A considerable literature has grown up around the theme of digital board in language learning. Therefore, this paper aims at finding the significance of developing a digital board game for the purpose of vocabulary learning. Fifty-seven (57) students from Universiti Malaysia Pahang (UMP) were selected as samples using purposive random sampling to collect data for the current study. A questionnaire was employed to explore their needs of a digital board game to learn vocabulary. The findings revealed that digital board game has significant needs among students to learn vocabulary, and further support the idea of using digital board game in language classroom. Majority of them believed that digital board game may provide a significant impact on vocabulary learning. Overall, the current study proves to be particularly valuable to language teachers to incorporate digital board game into their instructional activity. Also, these findings suggest a role for interactive learning in motivating language learner to enrich their vocabulary size.
\end{abstract}

\section{Introduction}

It is a challenge for educators to keep the students' learning interest. Yet, learning while playing is one way that helps students to become passionate in their learning. It also helps to stimulate their interest in learning. The use of conventional board games is seen much beneficial to students as it is engaging them in playing while learning. However, with the emergence of technology, digital board games are more suitable to the interest of students nowadays [1]. Learning a language can be at ease with the existing games which are digitized. From learning the language in various skills such as reading, speaking, listening or writing, digital board games can also be used to learn vocabularies of a language. This study, therefore, explores whether or not there is a need of using digital board game in learning English, specifically vocabulary among tertiary level students.

It is important to understand that computer and games are enormously powerful learning tools, even though they are most often thought of as pure entertainment. Technology will not only help us to design better games but will also allow us to create effective new learning opportunities and tools. In designing digital game-based learning, two key premises need to be adhered to. First, learners demonstrate changes in some fundamentally important ways and second, computer games can provide a new way to motivate students to learn [2]. Moreover, successful learning mostly occurs when learning is more relevant and reflective to learners. This is true for board game as it is a game that is made of a text description, illustration cards, a game board and some simple properties. In fact, a good game design can maintain players' motivation and engagement [3]. In relation to the use of conventional board game in education, a good educational game design can keep learners engaged in learning. Yet, board game that is digitalized may amuse the participants or players to play the game. In addition, the teachers may provide more time paying attention to students' performance, rather than busy placing associated conversational cards in front of the learners.

\section{Methodology}

\subsection{Research Sample}

A total of fifty-seven (57) diploma and undergraduate students in Universiti Malaysia Pahang were selected as the samples of the current study. All of them were engineering students who, during the collection of the data were in their first, second and third year of study. A purposive random sampling was employed in selecting the qualified participants. This type of sampling is the most popular and rigorous form of probability sampling from a population under study and the advantage of it is

* Corresponding author: zuraina@ump.edu.my 
any bias in the population will be equally distributed among the people chosen [4].

\subsection{Research Instrument}

As for the instrument used, an online questionnaire was developed by using Google form and it consisted of three main sections. Section 1 concerns with the participants' demographic information such as gender, level of education, ethnicity, faculty and the semester of studying in UMP. On the other hand, Section 2 consists of two questions asking the participants about their familiarity of playing digital/online games and a list of options were provided for each question. The last part; Section 3 contains nine items - eight items are of 5-point Likert scale where the samples are asked to rate their needs for a digital board game and the last item is an open ended question in which they need to explain one significant way that digital board game may help them in their learning.

\subsection{Research Procedures}

In collecting the data for the current study, the researchers first set up the online questionnaire by using Google form. The reasons for using online questionnaire, particularly Google form were mainly because of its administration speed in which it can reach the participants faster and lower cost incurred as no budget spent on the photocopy purposes. After the set up was completed, the link to the questionnaire was shared to the participants, either through Edmodo or email. Prior to the administration of the questionnaire, the participating students were informed about the purpose of the study and the confidentiality of the results. Generally, each participant spent less than twenty minutes to complete the questionnaire. The obtained data was then analyzed using simple statistical analysis. Meanwhile, data that was gathered qualitative; more specifically interviews, were coded. Hence in reporting the results of the study 'P11' stands for 'Participant 11', 'P14' refers to 'Participant 14'; respectively. Figure 1 shows the research procedures of collecting the data for the study.

Basically, there are four (4) basic steps that were involved in the procedures and these are preparing an online questionnaire, identifying research sample, distributing questionnaire and analyzing data. These stages of collecting data took about a month in which researchers brainstormed to develop the items for the questionnaire. Several meetings were conducted to finalize the set of questionnaire. Later, a google form was created where all items were placed according to their suitable sections. Moreover, in identifying the participants that would be involved in the current study, it was decided that they would be the students that registered in the researchers' classes themselves. In distributing the questionnaire, the researchers had to ensure that students were not disturbed in conducting task. Therefore, they were informed of the link to click the via electronic communications.

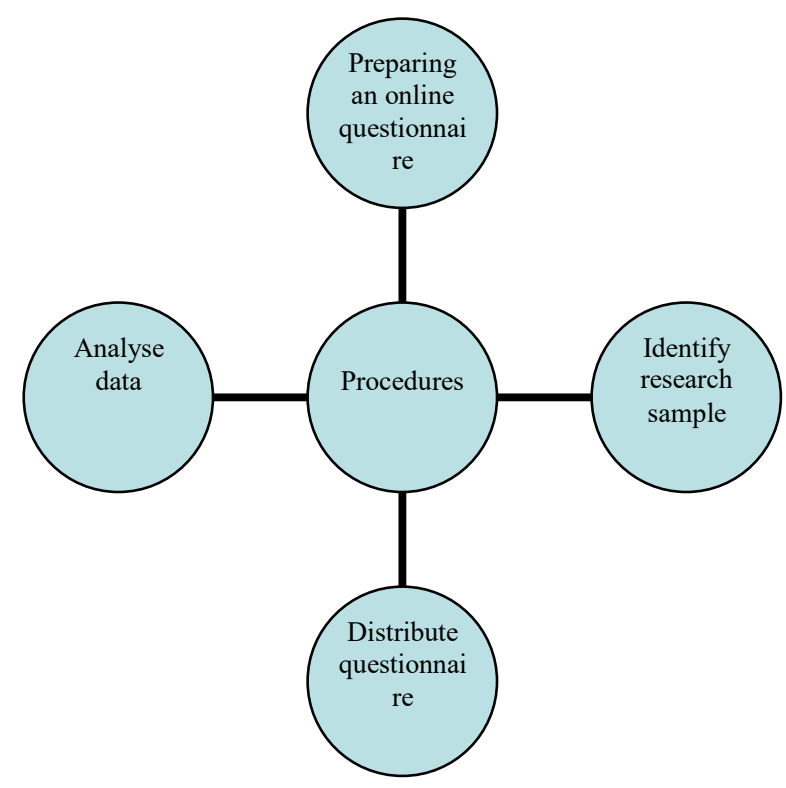

Fgure 1: Procedures of Collecting Data for the Study

\section{Results and Discussion}

The study aims to identify the need for a digital board game among tertiary students in learning English language. A simple statistical analysis was employed for the study. Also, the study presents qualitative findings to further elaborate the quantitative findings.

In general, these results indicate a significant need for a digital board game in learning English language. The participants provided positive feedback when asked on their views on the use of a digital board game in their language learning. Table 1 illustrates the data obtained from the questionnaire counting the percentage of students' responses in answering their views on the needs for a digital board game. In the table, it is apparent that majority of the participants $(84.2 \%)$ agreed with Item 3 'Vocabulary digital game enrich a player's vocabulary size'. One of the participants commented that "it [digital board game] allows players to widen their vocabulary choices". The view was echoed by P11, P14, and P21 in which they felt that "while playing [digital board game], I can learn English vocabulary". These results are in accord with a previous study as they found that the incorporation of digital content into language learning can increase the students' vocabulary size [5]. The learning of vocabulary through digital learning environment helps to cater to different and unique individual's learning style. Similarly, another finding further supports the idea of incorporating digital learning into vocabulary learning in which the researcher found that the participants' vocabulary size increased significantly after learning from Quizlet [6]. This is very much true since learning is fruitful when it matches with students' learning aptitude [7]. The study reported that three (3) methods of vocabulary learning; namely 
contextual clues, dictionary strategy and Computer Assisted Language Learning (CALL) - in particular Tell $\mathrm{Me}$ More from Auralog, were employed to identify tertiary level students' ability in learning vocabulary. A post hoc test using Gabriel test (Anova) showed that students showed more positive attitudes when computers were employed in the students' learning of vocabulary compared to two other methods. The software that is interactive provides its learners with speech recognition technology and that it assists them to learn various languages (i.e. English, Spanish, Mandarin and others) in general, and vocabulary in particular with 37 different types of engaging activities. Moreover, the result is in the lines of earlier literature which found that students were able to widen their vocabulary as well as improve their language skills when they were able to play with other community of players [8]. The state-of-the-art for the kind of learning is described as gameplay-as-learning practices. Over a hundred tertiary level students took part in the study. They were reported to take active roles as gamers in building their community of gamers. Five (5) gamers whom their communication in forums were recorded, demonstrated that they communicated for game information and gameplay strategies.

Meanwhile, in response to Item 2, 82.5\% agreed that 'Language digital game can improve a player's understanding of language'. According to the participants, digital board game can function as a tool to gain deeper understanding of English language. P32 noted that "it helps me to improve my [English] language and I can know my weakness in that language" and eventually, P1 noted that "I can improve my academic results". As for $\mathrm{P} 2$ and $\mathrm{P} 19$, they believed that the use of digital board game can assist them in learning grammar and other language skills. Meanwhile, [9] examined teachers' perception on the use of digital games. The outcomes were positive as the teachers noted the students were actively engaged throughout the lesson and motivated them to learn the language. For Item 1, equal number of participants $(\mathrm{N}=37)$ agreed to the statement in which participants responded that a digital board game can be played at leisure hours as they perceived the use of digital board game as fun and interactive language learning tool. P34 alluded that "with interesting educational games, I will be able to make learning a fun process" while P20 further elaborated that "it [digital board game] is memorable due to its unique and simple" approach of language learning. Furthermore, they can learn language in a stress-free environment as mentioned by P24, "when playing, we do not [feel] stress so it is easier for us to learn..." It is, in fact, in line with a previous study in which the respondents believed that learning digitally can make the experience more interesting and enjoyable [10]. Nevertheless, playing digital board games may not only be for learning as it may provide a popular pastime for all ages of life and genders. Playing the game enables its player to test his or her skill as in playing Chess and Poker or test someone's luck when he or she plays games; for instance Yahtzee and Pass the Pigs. The results of the study further support the idea that a digital board game provides students with a stress-free environment [11]. Such was demonstrated when forty participants expressed that there had more freedom to explore and move about when they play Tisch; a digital board game that provides interactive and interesting platform for its players to engage with. This is due to the fact that its players are able to monitor their potential as they may play various activities in the digital board game according to their preferences. Consistent with a series of article reviews pertaining to integrating games in language learning, mobile games are shown to be stress-free tools [12] that enable players to learn vocabulary in more contextualized manner. In fact, it is one approach that teachers may consider to ensure that classes would be interesting and effective. This mobile learning vocabulary games are able to help players/learners to improve their domain of vocabulary knowledge.

Overall, these results suggest that there is a significant need for a digital board game to be used by tertiary students to learn English language. It can be summarized that it is fundamental to develop a digital board game since the tool enables its players to play at their time and space, improve players' understanding of a language and enrich players' vocabulary size.

Table 1. Students' Perceptions of Need for Digital Board Game

\begin{tabular}{|l|l|c|c|}
\hline No. & \multicolumn{1}{|c|}{ Items } & $\begin{array}{c}\text { Frequency } \\
\text { (N) }\end{array}$ & $\begin{array}{c}\text { Percentage } \\
\text { (\%) }\end{array}$ \\
\hline 1. & $\begin{array}{l}\text { A digital board } \\
\text { game can be played } \\
\text { at leisure hours }\end{array}$ & 37 & 64.9 \\
\hline 2. & $\begin{array}{l}\text { Language digital } \\
\text { game can improve } \\
\text { a player's } \\
\text { understanding of } \\
\text { language }\end{array}$ & 47 & 82.5 \\
\hline 3. & $\begin{array}{l}\text { Vocabulary digital } \\
\text { game can enrich a } \\
\text { player's vocabulary } \\
\text { size }\end{array}$ & 48 & 84.2 \\
\hline
\end{tabular}

Having stated the results of the current study, it may require that in the actual study, potential participants may need to be assigned to play the game outside the class hours. Such is considered due to ample time is forecast to be the factor that would engage players to play the game. Moreover, they may choose their coplayers that are online at that particular time to play the game. Yet, before gauging their experiences of playing the board game, preparing story board is a requirement on part of the researchers. Due to the researchers' exposures of having to develop an online vocabulary game namely OnVac and a vocabulary app - VocBlast, it is hoped that a digital board game can be materialized through the concepts provided in the current study. 


\section{Conclusion}

In this paper, the researchers aim at identifying the need for a digital board game among tertiary students in learning English language specifically in vocabulary learning. From the findings, it seems clear that majority of the participants believed that digital board game help to increase their vocabulary size. Learning vocabulary can be challenging sometimes and if conventional method is used throughout, the learning would result in years. Digital board game may be the alternative to let the students experimenting new vocabulary instead of memorizing it.

The participants also displayed positive attitude toward the use of language digital game in enhancing their understanding of the language which at the same time enhance their motivation to learn the language. Upgrading the board game digitally is an idea that is celebrated by majority of the participants in the current study as it helped them to comprehend the language use in a vivid presentation. Moreover, by upgrading the board game digitally, the game is enhanced with variety of auditory and visual stimuli that makes it a perfect educational tool that provides enjoyment, pleasure and motivation to the students [13]. Moreover, it is believed that students would gain higher self-confidence when they manage to complete the targeted level. This succession of emotions tends to keep the players immersed.

This study also found that students perceived digital board game as fun and interactive language learning tool because it can be played at leisure hours. Indeed, digital board game provides stress free environment for the students, and thus, makes learning a fun process whereby they can collaborate with other students through sharing information and learn from each other without the presence of the teacher. The students can develop critical thinking, increase self-esteem and also improve their skill and knowledge through this collaborative approach.

With pedagogical considerations in mind, we believed digital board game is an exceptional educational tool as it helps to reinforce important knowledge in an easy to understand format, reduce the time needed to learn, memorize and apply new knowledge plus at the same time promote discussion, collaboration and build communication. In short, digital board game has many benefits when it designed appropriately for learning.

Although the current study employed a small number of sampling size, we believed this study has added to the body of knowledge pertaining to the effectiveness of using digital board game in order to achieve better results in vocabulary learning and language development. Digital board game also provides genuine, authentic, hands-on and heads-on skill and knowledge as well as engaging atmosphere yet at the same time competitive environment for the students to learn the content through game elements such as discussion, problem solving and making decision. That being said, it is about time the tertiary education shifts forward in teaching language by incorporating digital board game in language classroom.

\section{Recommendation}

Further work needs to be done to establish students' perceived usefulness of the actual digital board game in learning English in tertiary education based on the results obtained in the current study. Particularly, future researchers may be able to examine issues in the use of digital board game in terms of the game content. Further investigation also may be carried out looking at students' progress in using digital board game to learn English language.

This research was supported by Universiti Malaysia Pahang (UMP) under research grant no. RDU1603144.

\section{References}

1. Agca, R. K., \& Ozdemir, S. Foreign Language Vocabulary Learning with Mobile Technologies. Procedia - Social and Behavioral Sciences 83, 781785 (2013)

2. Prensky, M. Computer Games and Learning: Digital Game-Based Learning. (2007).

3. Pea, R.D. et al. Methods and apparatus for interactive map-based analysis of digital video content. Retrieved from https://www.google.com/patents/US7082572

4. Cresswell, J. W. Educational research: Planning, conducting, and evaluating quantitative and qualitative research (3rd ed.). New Jersey: Pearson Education (2007)

5. Agca, R. K., \& Ozdemir, S. Foreign Language Vocabulary Learning with Mobile Technologies. Procedia - Social and Behavioral Sciences 83, 781785 (2013)

6. Dizon, G. Quizlet in the EFL Classroom: Enhancing Academic Vocabulary Acquisition of Japanese University Students. Teaching English with Technology, 16 (2), 40-56 (2016)

7. Ali, Z., Mukundan, J., Baki, R., \& Ayub, A. F. M. (2012). Second language learners' attitudes towards the methods of learning vocabulary. English Language Teaching, 5(4), 24.

8. Chik, A. Digital gaming and language learning: Autonomy and community 18 (2), 85-100. (2014)

9. Huizenga, J., Dam, G. t., Voogt, J., \& Admiraal, W. Teacher Perceptions of the Value of Game-Based Learning in Secondary Education. Computers \& Education 110, 105-115 (2017)

10. Mora, S., Di Loreto, I., \& Divitini, M. (2016). From interactive surfaces to interactive game pieces in hybrid board games. Journal of Ambient Intelligence and Smart Environments, 8(5), 531-548.

11. Bergström, K., \& Björk, S. (2014). The case for computer-augmented games. Transactions of the Digital Games Research Association, 1(3).

12. Derakhshan, A., \& Elham, D. K.. The effects of using games on English vocabulary learning. Journal of Applied Linguistics and Language Research, 2 (3), 39-47. (2015) 
13. Muhammad Sabri Sahrir, Nurkhamimi Zainuddin, \& Mohd Shahrizal Nasir. Learning Preference among Arabic Language Learners via Mobile Learning Management System Platform (Mobile LMS) using I-Taleem. International Journal of Current Research in Life Sciences 5 (1), 509-514 (2016) 